\title{
Adsorption of Free Fatty Acid from Crude Palm Oil on Magnesium Silicate Derived From Rice Husk
}

\author{
Weerawat Clowutimon, Prakob Kitchaiya, and Pornsawan Assawasaengrat* \\ Department of Chemical Engineering, Faculty of Engineering, \\ King Mongkut's Institute of Technology Ladkrabang, Bangkok, 10520 Thailand \\ E-mail: kkpornsa@kmitl.ac.th*
}

\begin{abstract}
Magnesium silicate with various silica and magnesium oxide ratios $\left(\mathrm{SiO}_{2} / \mathrm{MgO}\right.$ ratios) was used as the adsorbent for a study of adsorption of free fatty acid (FFA) in crude palm oil (CPO). Magnesium silicate was prepared from magnesium nitrate or magnesium sulfate solution precipitated with a solution of sodium silicate derived from rice husk. $\mathrm{SiO}_{2} / \mathrm{MgO}$ ratios of the magnesium silicate synthesized from magnesium nitrate and magnesium sulfate were 3.93, 3.75, 2.74, 2.40, 1.99 and 3.96, $3.61,3.51,2.91,2.69$, respectively. FFA adsorption on the magnesium silicate was carried out by adding 1 gram of the adsorbent to 50 grams of CPO and shaking for 1 hour at $50^{\circ} \mathrm{C}$. It was found that $\mathrm{SiO}_{2} / \mathrm{MgO}$ prepared from magnesium nitrate ratio of 1.99 had the highest adsorption capacities of $185 \mathrm{mg}$ of FFA per gram of adsorbent. In addition, increasing of $\mathrm{SiO}_{2} / \mathrm{MgO}$ ratios of magnesium silicate was found to reduce the adsorption capacities due to decreasing of FFA chemisorption. The effect of dosage amount to equilibrium adsorption capacities were carried out by adding different amount of magnesium silicate $\left(\mathrm{SiO}_{2} / \mathrm{MgO}\right.$ ratio of 1.99) to 50 grams of $\mathrm{CPO}$. The result showed that efficiency decreased when dosage increased. The Fruendlich and Langmuir isotherm were applied to describe this absorption system. The values of maximum sorption capacity $\left(\mathrm{Q}^{0}\right)$ and Langmuir's sorption affinity (b) in the Langmuir equation obtained by linear-regression were minus values which were physically meaningless. Thus, FFA adsorption on magnesium silicate was both physisorption and chemisorption and well represented by the Fruenlich isotherm.
\end{abstract}

Keywords: Adsorption, free fatty acid, magnesium silicate, rice husk.

ENGINEERING JOURNAL Volume 15 Issue 3

Received 21 February 2011

Accepted 4 May 2011

Published 1 July 2011

Online at http://www.ej.eng.chula.ac.th/eng/

DOI:10.4186/ej.2011.15.3.15 


\section{Introduction}

Thailand is one of the world's biggest rice producers, the output was 27 Million tonnes in 2001 and it was the world's biggest rice exporter. Rice husk, a waste co-product of the rice industry, contains over $60 \%$ silica and is evaluated as a raw material for production of a number of silica based products. When harvested from field, rice kernels are fully enveloped by rice husk. After being harvested, the first stage in milling is removal of husk. Annually, Thailand had 5.4 million tonnes of rice husk. Rice husk comprises $15-20 \%$ of kernel [1], and mainly contains lignin, cellulose, hemicellulose and silica. Rice husk contains $13-29 \%$ wt of silica [2]. When rice husk is combusted at over $400^{\circ} \mathrm{C}$ to produce rice husk ash, organic compounds are decomposed to carbon dioxide result in rice husk ash having higher silica content. Acid treatment of rice husk before combustion provides an ash product of higher silica content than the one that not thorough acid treatment. By this treatment at a suitable condition, rice husk ash may consist of $99.8 \%$ wt of silica [3]. Rice husk and rice husk ash have become a source for a number of silicon compound, including silicon carbide, silicon nitrite, silicone tetrachloride, pure silicon [2], zeolite, silica, silica gel, sodium silicate and magnesium silicate, etc. [3, 4]. Magnesium silicate is an adsorbent for contaminants in bio-diesel production [5] or an adsorbent for FFA in CPO [6].

$\mathrm{CPO}$ is used as a raw material in bio-diesel production and it contains 3-4 \%wt of FFA. FFA is an obstruction for biodiesel production. It can react with base and transform to soap that reduces the efficiency of biodiesel. Base is used to neutralize FFA or FFA esterification catalyzed by an acid catalyst could reduce FFA. Both methods are costly and process difficulty. Adsorption is an alternative to reduced FFA from CPO that the separated FFA can be sold as a byproduct.

In this paper, an adsorbent, namely magnesium silicate, was synthesized from rice husk and used to adsorb FFA from CPO.

\section{Experiment methods}

Rice husk sample was received from rice mills in Nakornpathom province, Thailand. Preparation procedure followed a previous work by Santi [2]. Rice husk was boiled in 3M hydrochloric acid for $3 \mathrm{hr}$, then washed with distilled water until the washed water was neutral. The rice husk was dried at $100^{\circ} \mathrm{C}$ for $12 \mathrm{hr}$, and finally combusted at $700^{\circ} \mathrm{C}$ for $2 \mathrm{hr}$. Sodium silicate preparation method followed the experimental procedure similar to what reported by Suthida [4]. 4.4g of rice husk ash was boiled with $1.6 \mathrm{~g}$ of sodium hydroxide in $100 \mathrm{ml}$ of water at $130^{\circ} \mathrm{C}$ until the solution volume was remaining $50 \mathrm{ml}$. Then it was filtered to separate carbon residue. Measurement of silica content from sodium silicate solution followed the experimental procedure suggested by Anorat [3]. The silica content of this solution was found to be 7.5-7.7\% wt.

The next step was the precipitation of magnesium silicate. $50 \mathrm{ml}$ of the prepared sodium silicate solution was mixed with $70 \mathrm{ml}$ of $0.1,1,2,3$ and $4 \mathrm{M}$ of magnesium nitrate solution at room temperature. The precipitate was dried at $100^{\circ} \mathrm{C}$ for $12 \mathrm{hr}$, then mashed and activated at $680{ }^{\circ} \mathrm{C}$ for 40 minutes.

Chemical characterization of representative sample was undertaken by X-ray fluorescence spectrophotometer (XRFs) for major element detection. Analysis by X-ray diffractrometer (XRD) revealed major crystalline phases in magnesium silicate samples. Structural characterization of the sample was investigated by Fourier transform infrared spectrometer (FT-IR).

In order to determine magnesium silicate adsorptive properties, their BET specific surface area and pore diameter were estimated using multipoint BET surface area, and meso pore volumes was determined by using BJH equation. A method to determine the number of acid site on adsorption site was the titration of amine with Hammett acidity distribution by using methyl red as the indicator.

Comparative efficiency of FFA adsorption on magnesium silicate derived from rice husk and commercial magnesium silicate was investigated. $50 \mathrm{~g}$ of CPO was added to $2 \mathrm{~g}$ of magnesium silicate in a $250 \mathrm{ml}$ conical flask and the mixture was shaken at $180 \mathrm{rpm}$ at $50{ }^{\circ} \mathrm{C}$ for $1 \mathrm{hr}$. Then the adsorbent was separated from $\mathrm{CPO}$ and the amount of remaining FFA was determined by acid value titration according to AOCS. Official Methods Cd 3a-63.

For FFA adsorption on magnesium silicate derived from magnesium nitrate, the above procedure was repeated, except $1 \mathrm{~g}$ of adsorbent was added to $50 \mathrm{~g}$ of CPO.

Magnesium silicate had highest FFA adsorption capacity was selected to study the influence of the amount of the adsorbent and the contact time to reach the equilibrium. Therefore, the amount of 
adsorbent and contact time were varied as following, $0.25,0.5,1,1.5$ and $2 \mathrm{~g}$ of adsorbent per $50 \mathrm{~g}$ of $\mathrm{CPO}$ and contact time of 5,9 and $13 \mathrm{hr}$, respectively.

FFA adsorption isotherm was determined by using magnesium silicate to adsorb CPO. FFA mixtures at different concentration were prepared by dilution with refined palm oil. To ensure that adsorption equilibrium was reached, adsorption time was left $13 \mathrm{hr}$. Langmuir isotherm was plotted as $\mathrm{mg}$ of FFA adsorbed per gram of adsorbent vs. residual concentration of FFA in solution. An $\mathrm{ln} / \mathrm{ln}$ plot was also prepared to observe the Freundlich constant, $\mathrm{K}$ and $\mathrm{R}^{2}$ was determined by using linear Regression.

\section{Result and Discussion}

Synthesized magnesium silicate was the fine white powder. Table 1 shows the components of commercial magnesium silicate and magnesium silicate derived from rice husk. Obviously, higher concentration of magnesium nitrate or magnesium sulfate provided magnesium silicate precipitates with lower $\mathrm{SiO}_{2} / \mathrm{MgO}$ ratio. Thus, it could be able to prepare the desired $\mathrm{SiO}_{2} / \mathrm{MgO}$ molar ratio of magnesium silicate at a wide range by precipitation. At higher molar ratio of $\mathrm{SiO}_{2} / \mathrm{MgO}$, magnesium silicate could not be precipitated due to a dilute solution. Magnesium solubility in water limited the lower molar ratio of prepared magnesium silicate.

Table 1. Chemical compositions of commercial magnesium silicate and magnesium silicate derived from rice husk.

\begin{tabular}{|c|c|c|c|c|c|}
\hline \multirow{2}{*}{$\begin{array}{l}\text { Solution of } \\
\text { precipitation }\end{array}$} & \multirow{2}{*}{$\begin{array}{c}\text { Concentration } \\
(\mathrm{M})\end{array}$} & \multicolumn{3}{|c|}{$\% \mathrm{wt}$} & \multirow{2}{*}{$\begin{array}{r}\text { Molecular } \\
\text { ratio of } \\
\mathrm{SiO}_{2} / \mathrm{MgO} \\
\end{array}$} \\
\hline & & $\mathrm{SiO}_{2}$ & $\mathrm{MgO}$ & Other & \\
\hline \multirow{5}{*}{ Magnesium nitrate } & 0.5 & 83.2 & 14.1 & 2.7 & 3.93:1 \\
\hline & 1 & 81.2 & 14.4 & 4.4 & $3.75: 1$ \\
\hline & 2 & 76.4 & 18.6 & 5 & $2.73: 1$ \\
\hline & 3 & 75.1 & 20.8 & 4.1 & $2.40: 1$ \\
\hline & 4 & 71.6 & 23.9 & 4.5 & 1.99:1 \\
\hline \multirow{5}{*}{ Magnesium sulfate } & 0.5 & 83.9 & 14.1 & 2 & $3.96: 1$ \\
\hline & 1 & 81.8 & 15.1 & 3.1 & $3.61: 1$ \\
\hline & 2 & 81.1 & 15.4 & 3.5 & $3.51: 1$ \\
\hline & 3 & 78.6 & 18 & 3.4 & $2.91: 1$ \\
\hline & 4 & 75.2 & 18.6 & 6.2 & 2.69:1 \\
\hline \multicolumn{2}{|c|}{ Commercial magnesium silicate } & 67.9 & 28.4 & 3.7 & $1.59: 1$ \\
\hline
\end{tabular}

XRD patterns of magnesium silicate from rice husk and commercial magnesium silicate are demonstrated in Fig. 1. The structure of synthesis magnesium silicate appeared to be amorphous phase. The XRD patterns of the derived ones were in an agreement with the commercial magnesium silicate.

Table 2 shows the specific surface areas, pore diameters and meso pore volumes of magnesium silicate from rice husk, and in the range of $230-360 \mathrm{~m}^{2} / \mathrm{g}, 57-85 \mathrm{~A}^{\circ}$ (mesopore) and $0.39-0.64 \mathrm{~cm}^{3} / \mathrm{g}$, respectively. Molecular ratio of $\mathrm{SiO}_{2} / \mathrm{MgO}$ was 1.99 that had largest pore diameter and pore volumes, $85 \mathrm{~A}^{\circ}$ and $0.64 \mathrm{~cm}^{3} / \mathrm{g}$, respectively. 

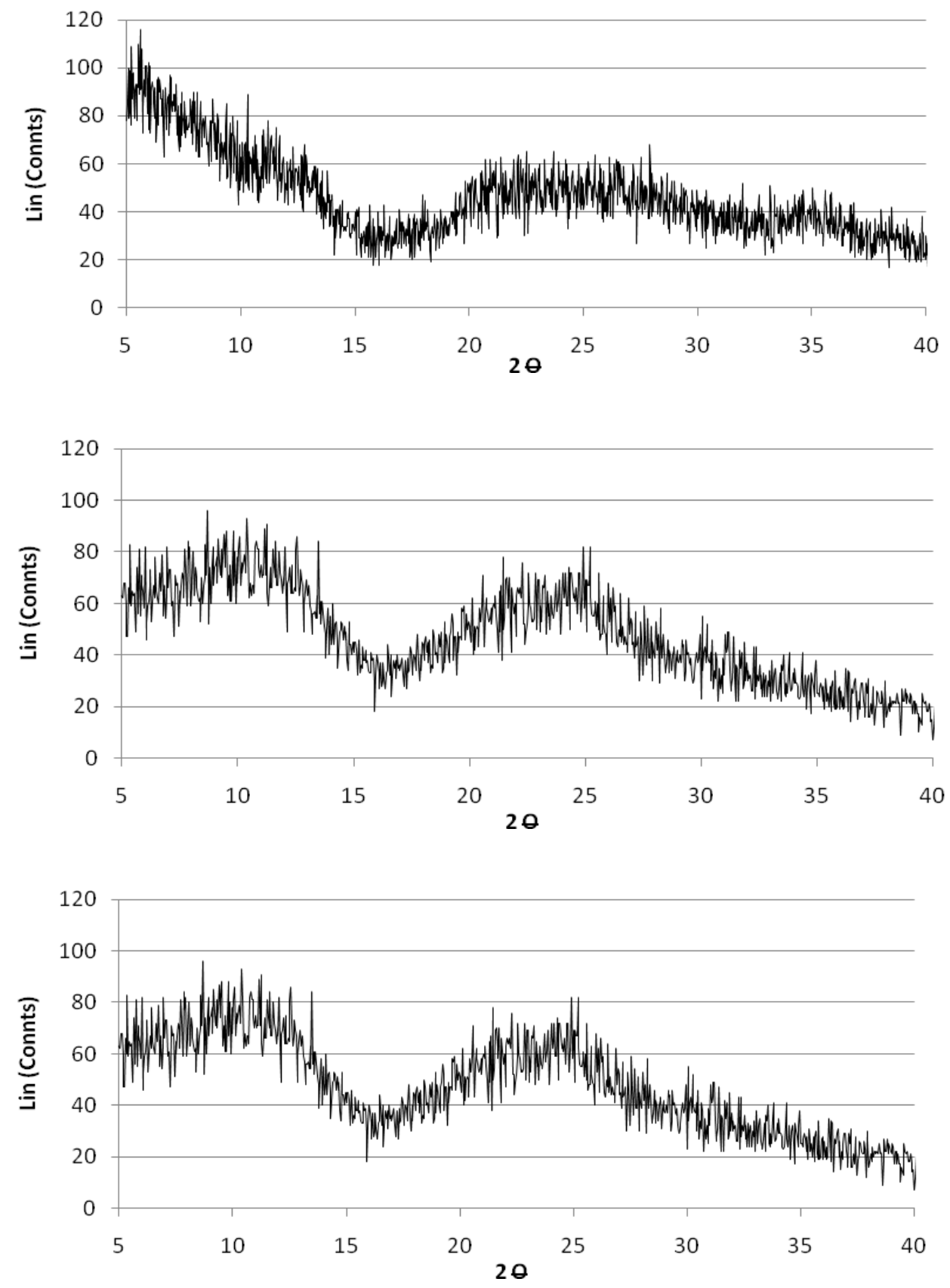

Fig. 1. XRD patterns of magnesium silicate from precipitated from

(A) magnesium nitrate, ratio of 1.99

(B) magnesium sulfate, ratio of 2.69

(C) commercial magnesium silicate. 
Table 2. Specific surface areas, pore diameters and mesopore volumes of magnesium silicate from rice husk.

\begin{tabular}{cccc}
\hline $\begin{array}{c}\text { Molecular ratio of } \\
\mathrm{SiO}_{2} / \mathrm{MgO}\end{array}$ & surface area $\left(\mathrm{m}^{2} / \mathrm{g}\right)$ & $\begin{array}{c}\text { pore diameter } \\
\left(\mathrm{A}^{\circ}\right)\end{array}$ & $\begin{array}{c}\text { meso pore volume } \\
\left(\mathrm{cm}^{3} / \mathrm{g}\right)\end{array}$ \\
\hline $3.93: 1$ & 356.7 & 57.74 & 0.53 \\
$3.75: 1$ & 230.6 & 79.93 & 0.41 \\
$2.73: 1$ & 278.9 & 63.76 & 0.39 \\
$2.40: 1$ & 270.8 & 76.79 & 0.47 \\
$1.99: 1$ & 301.7 & 85.35 & 0.64 \\
\hline
\end{tabular}

The FT-IR spectra of magnesium silicate are shown in Fig. 2. These spectra were obtained from scanning in the range of $450-1650 \mathrm{~cm}^{-1}$. Peak spectra were very similar for 3 samples of magnesium silicate. The band represented vibration of siloxane bonding, $\mathrm{Si}-\mathrm{O}-\mathrm{Si}$, in magnesium silicate from rice husk, commercial magnesium silicate and silica was at 1075.2, 1028.41 and $1096 \mathrm{~cm}^{-1}$, respectively. The band of the synthesized magnesium silicate was much broader and more complex in the spectra. The broadening was likely due to the random presence of magnesium in the structure of magnesium silicate derived from rich husk. Similar results were observed for vibration of siloxane in commercial magnesium silicate and silica gel [7].

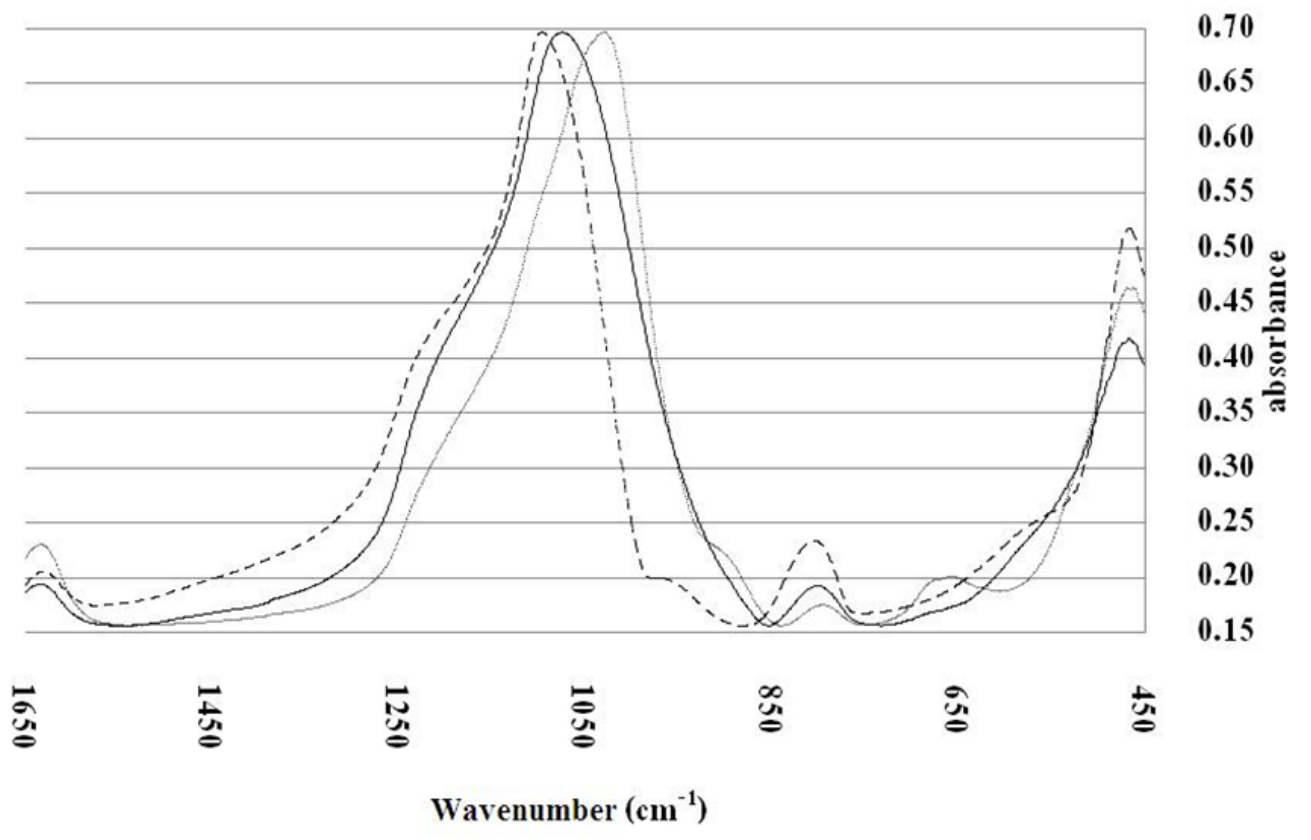

Fig. 2. FT-IR spectra of magnesium silicate from rice husk (-), commercial magnesium silicate (…..), and silica (---).

Acidic sites on the adsorbent were obtained by amine titration $[8,9]$ and using methyl red as Hammett indicator are shown in Fig. 3. The molecular ratio of $\mathrm{SiO}_{2} / \mathrm{MgO}$ of 1.99 represented maximum acidic sites and the solutions of precipitation not involved on the quantity of acidic site. It can be noticed that the amount of acidic sites decrease with increase of $\mathrm{SiO}_{2} / \mathrm{MgO}$ ratio of magnesium silicate. 


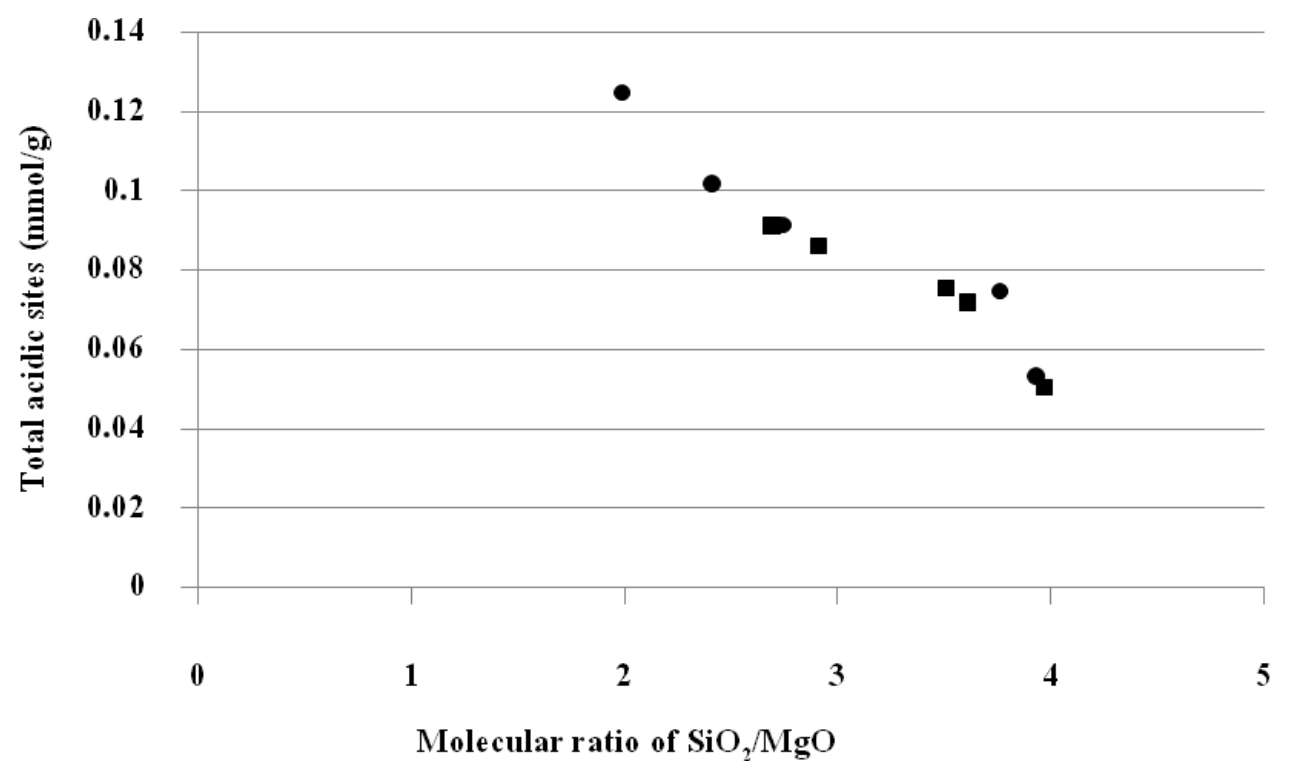

Fig. 3. Total acidic sites (mmol/g) versus molecular ratio of $\mathrm{SiO}_{2} / \mathrm{MgO}$ of magnesium silicate synthesized from magnesium nitrate $(\bullet)$ and magnesium sulfate $(\boldsymbol{\square})$.

Figure 4 demonstrates comparative efficiency on adsorption of FFA from $50 \mathrm{~g}$ of CPO using $2 \mathrm{~g}$ of magnesium silicate derived from rice husk and commercial magnesium silicate. Adsorption capacity of commercial magnesium silicate was $70 \mathrm{mg}$ FFA /g of adsorbent, while magnesium silicate from rice husk could adsorb 130-140 mg FFA per gram of adsorbent. For magnesium silicate from rice husk, there were similar adsorption results that could result from high dosage of adsorbents. Therefore reduced dosage of adsorbent to 1 gram per $50 \mathrm{~g}$ of crude palm oil was applied and shown in Fig. 5 . $\mathrm{SiO}_{2} / \mathrm{MgO}$ ratio of 1.99 had the highest adsorption capacities of $185 \mathrm{mg}$ of FFA per gram of adsorbent.

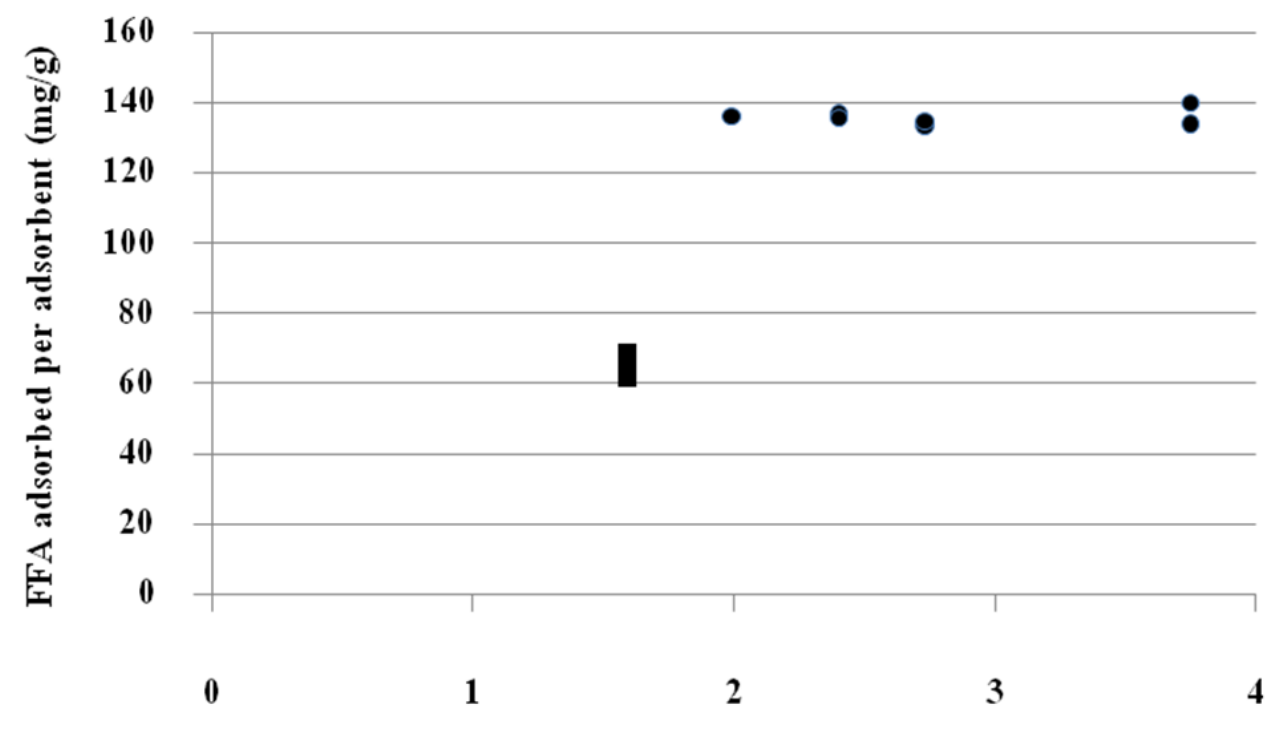

Molecular ratio of $\mathrm{SiO}_{2} / \mathrm{MgO}$

Fig. 4. FFA adsorbed per adsorbent (mg/g) versus molecular ratio of $\mathrm{SiO}_{2} / \mathrm{MgO}$ by using of $2 \mathrm{~g}$ of magnesium silicate derived from rice husk $(\bullet)$ and commercial magnesium silicate ( $(\bullet)$ for $1 \mathrm{hr}$. 


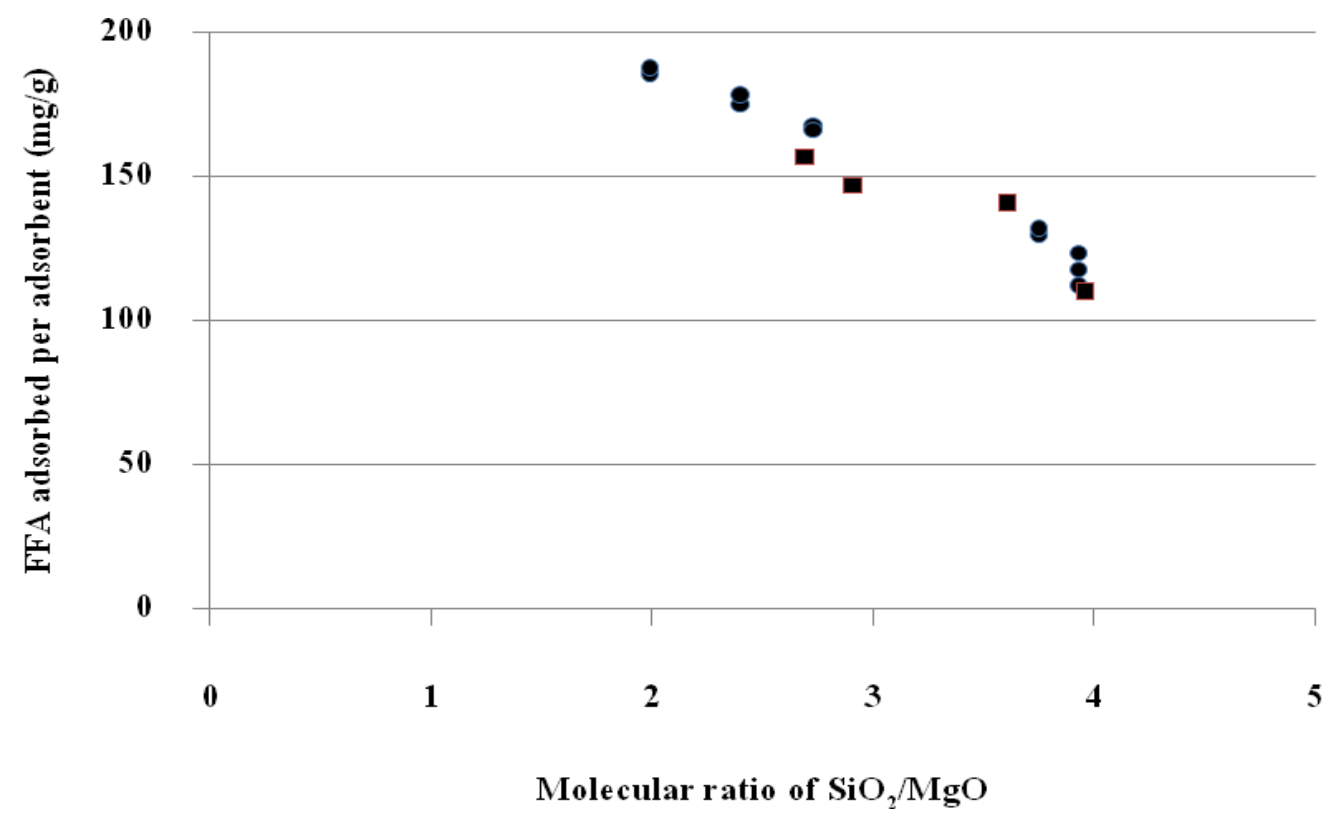

Fig. 5. FFA adsorbed per adsorbent (mg/g) versus molecular ratio of $\mathrm{SiO}_{2} / \mathrm{MgO}$ by using of $1 \mathrm{~g}$ of magnesium silicate derived from magnesium nitrate $(\bullet)$ and magnesium sulfate $(\boldsymbol{\bullet})$ for $1 \mathrm{hr}$.

In addition, increasing of $\mathrm{SiO}_{2} / \mathrm{MgO}$ ratios of magnesium silicate was found to reduce the adsorption capacities due to decreasing of FFA chemisorption.

Magnesium silicate with $\mathrm{SiO}_{2} / \mathrm{MgO}$ prepared from magnesium nitrate ratio of 1.99 which had the highest adsorbed free fatty acid was used to study the adsorption time to reach equilibria. Different quantity of magnesium silicate from rice husk and time to reach equilibrium were varied. They were $0.25,0.5,1,1.5$ and $2 \mathrm{~g}$ of adsorbent per $50 \mathrm{~g}$ of CPO and 5,9 and $13 \mathrm{hr}$, respectively. The adsorption results are shown in Fig. 6. It could be concluded that the equilibrium could be reached within $5 \mathrm{hr}$.

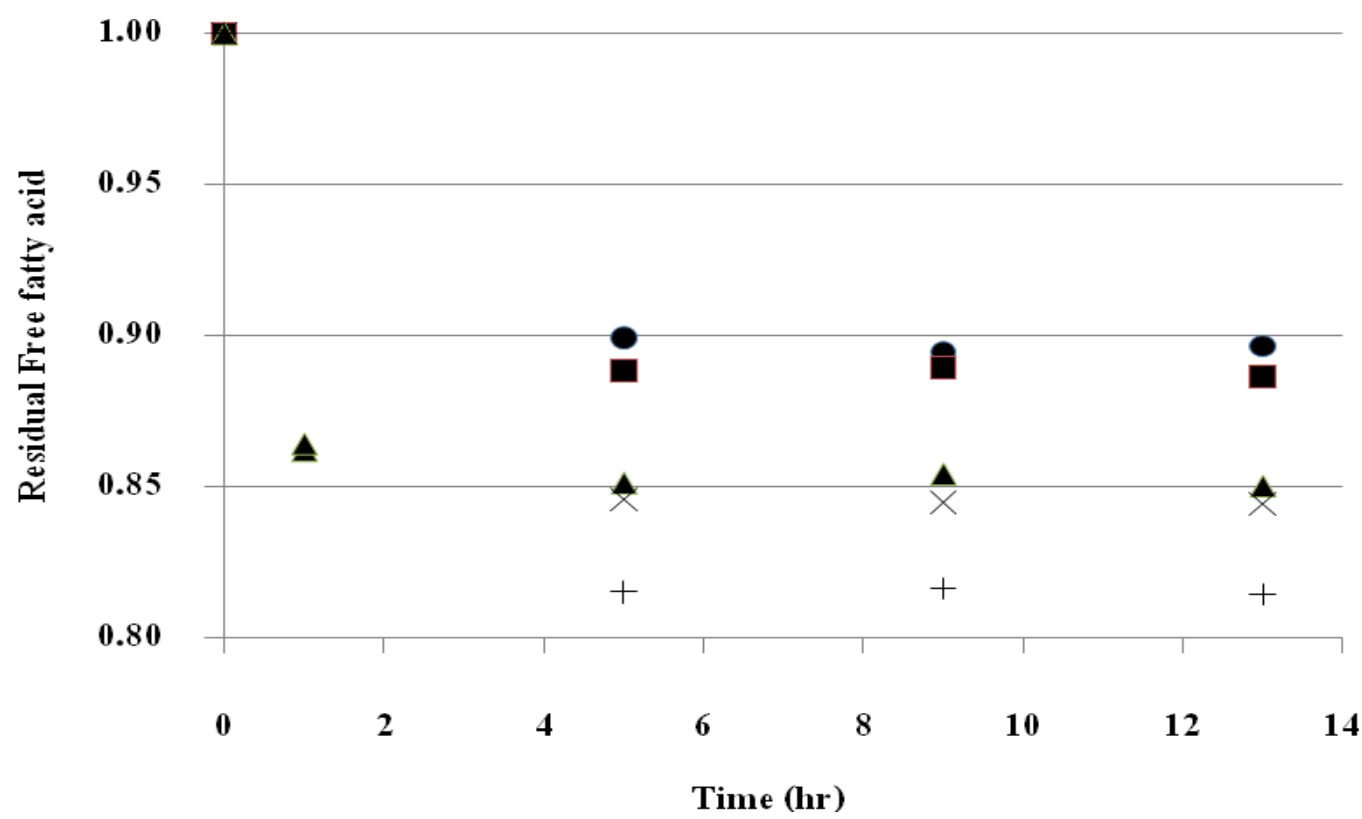

Fig. 6. Residual free fatty acid versus time (hr) on magnesium silicate with $\mathrm{SiO}_{2} / \mathrm{MgO}$ ratio of $1.99,(\bullet)$ $0.25 \mathrm{~g},(\mathbf{-}) 0.50 \mathrm{~g},(\mathbf{\Delta}) 1.00 \mathrm{~g},(\times) 1.50 \mathrm{~g}$ and $(+) 2.00 \mathrm{~g}$ per $50 \mathrm{~g}$ of crude palm oil at various times. 
Figure 7 shows that $0.25 \mathrm{~g}$ of magnesium silicate can adsorbed $587 \mathrm{mg}$ of FFA. Similar results were observed for adsorption of FFA from soy bean oil by rice hull ash [10].

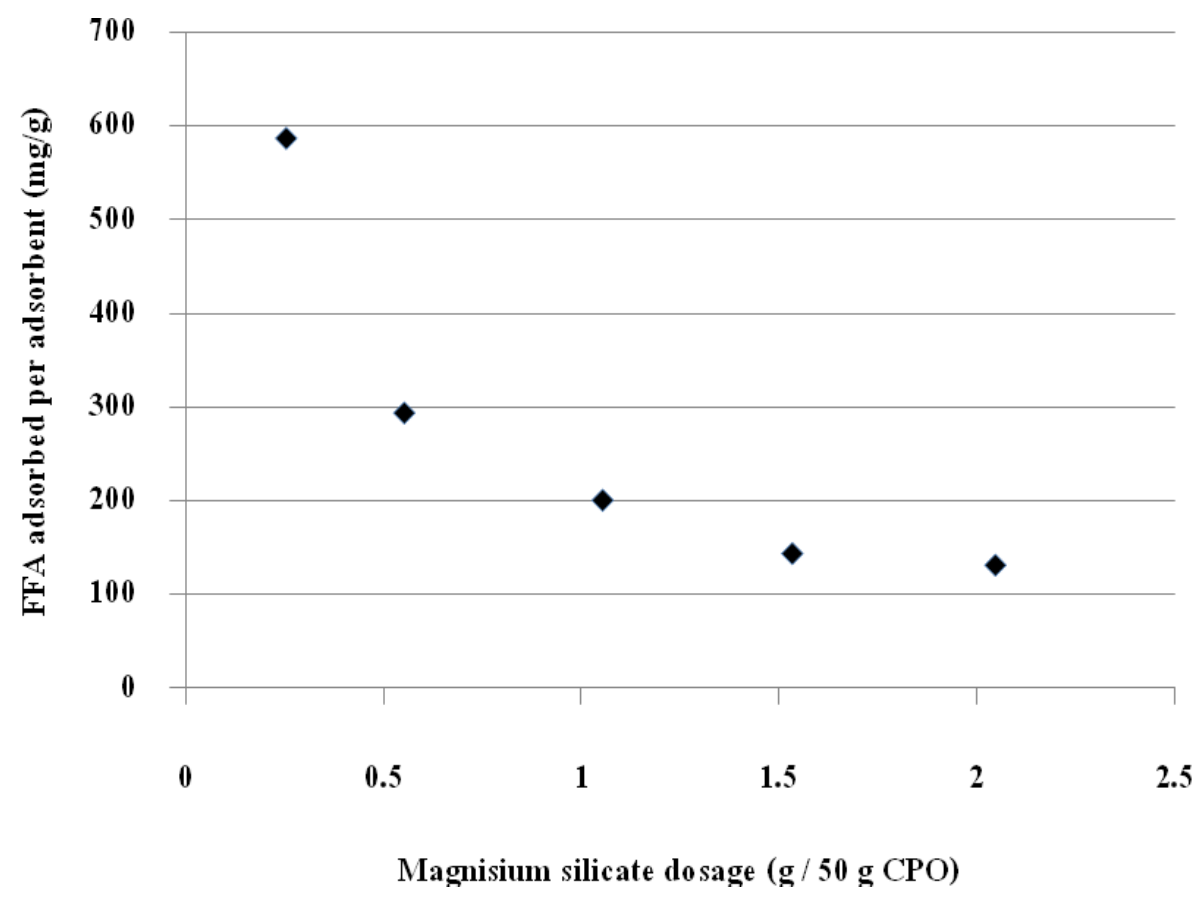

Fig. 7. FFA adsorbed per adsorbent versus Magnesium silicate dosage $\left(\mathrm{SiO}_{2} / \mathrm{MgO}=1.99\right)$ for $13 \mathrm{hr}$.

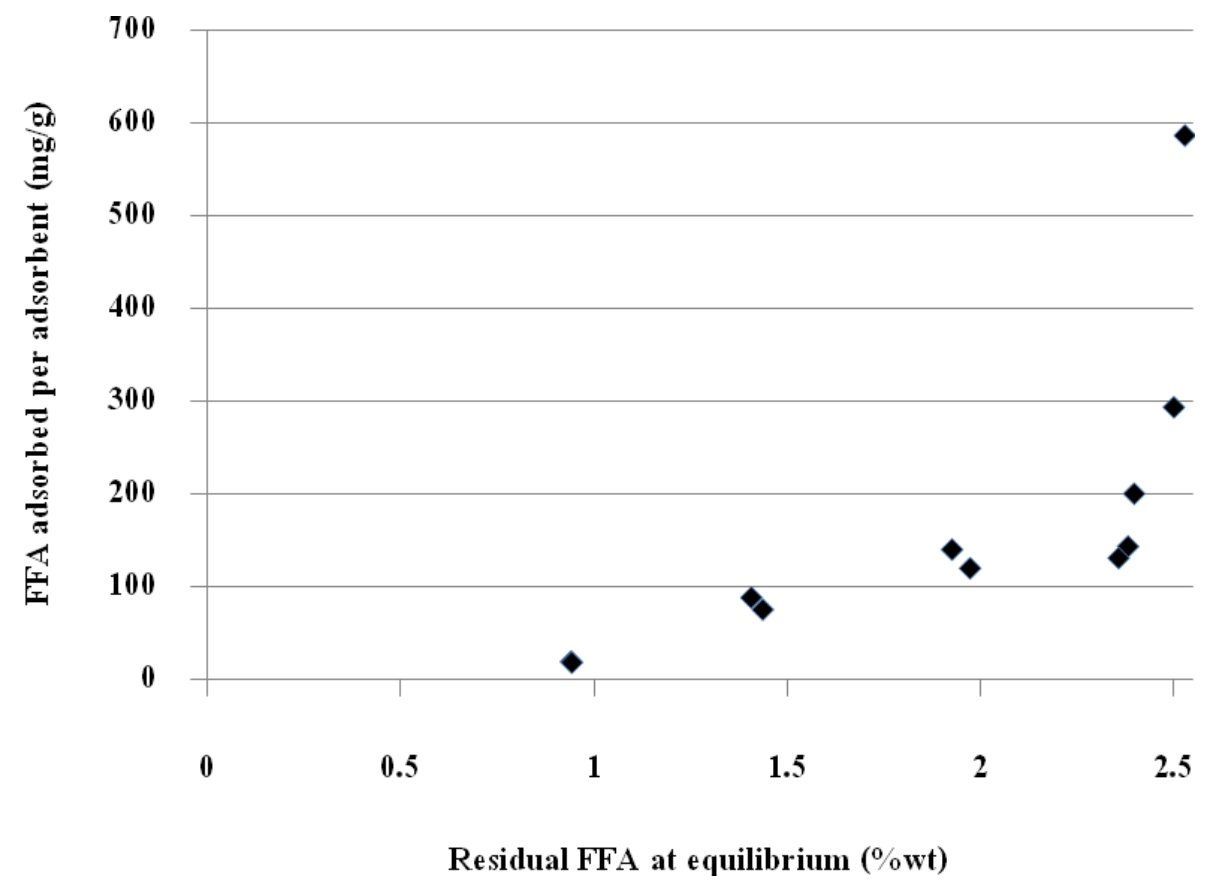

Fig. 8. FFA adsorbed per adsorbent versus residual FFA for $13 \mathrm{hr}$ on magnesium silicate derive from rice husk ash $\left(\mathrm{SiO}_{2} / \mathrm{MgO}=1.99\right)$. 
Adsorption isotherms can be represented by several numerous theoretical models where Langmuir and Freundlich models have been commonly used to fit experimental data. Langmuir isotherm assumes monolayer adsorption, and is presented by the following linearized equation:

$$
\frac{1}{q_{e}}=\frac{1}{Q^{0}}+\frac{1}{b Q^{0} C_{e}}
$$

where $q_{e}$ is equilibrium sorption capacity, $C_{e}$ is residual FFA in CPO at equilibrium $\mathrm{Q}^{0}$ is maximum capacity sorption and $b$ is Langmuir's sorption affinity, and the Freundlich linearized isotherm has the form:

$$
\ln q_{e}=\ln K_{F}+\frac{1}{n} \ln C_{e}
$$

where $\mathrm{K}_{\mathrm{F}}$ and $\mathrm{n}$ are Freundlich's constants.

The linearization of Langmuir and Freundlich isotherms for the adsorption of FFA from CPO are presented in Fig. 9 and 10, respectively. The model parameters are tabulated in Table 3. The Regression coefficients $\left(\mathrm{R}^{2}\right)$ were 0.906 and 0.868 for Langmuir and Freundlich model, respectively. Based on $\mathrm{R}^{2}$, Langmuir model was more promising to represent the adsorption data than another model. Therefore the experimental data could be better described by Freundlich isotherm than the Langmuir one. However the maximum sorption capacity $\left(\mathrm{Q}^{0}\right)$ and Langmuir's sorption affinity (b) were minus values which were physically meaningless.

\begin{tabular}{|c|c|c|c|c|}
\hline Model & Linear Equation & \multicolumn{2}{|c|}{ Constant } & $\mathrm{R}^{2}$ \\
\hline \multirow{2}{*}{ Langmuir } & $\underline{1}=-00264+00693 \frac{1}{1}$ & $\mathrm{Q}^{0}$ & -37.906 & \multirow{2}{*}{0.906} \\
\hline & $C_{e}$ & $\mathrm{~b}$ & -0.380 & \\
\hline \multirow[t]{2}{*}{ Freundlich } & $\ln q_{e}=3.226+2.545 \ln C_{e}$ & $\mathrm{~K}_{\mathrm{F}}$ & 25.186 & \multirow[t]{2}{*}{0.868} \\
\hline & & $1 / \mathrm{n}$ & 2.545 & \\
\hline
\end{tabular}

Table 3. Linear equation, constant and $\mathrm{R}^{2}$ of Langmuir and Freundlich Model. 


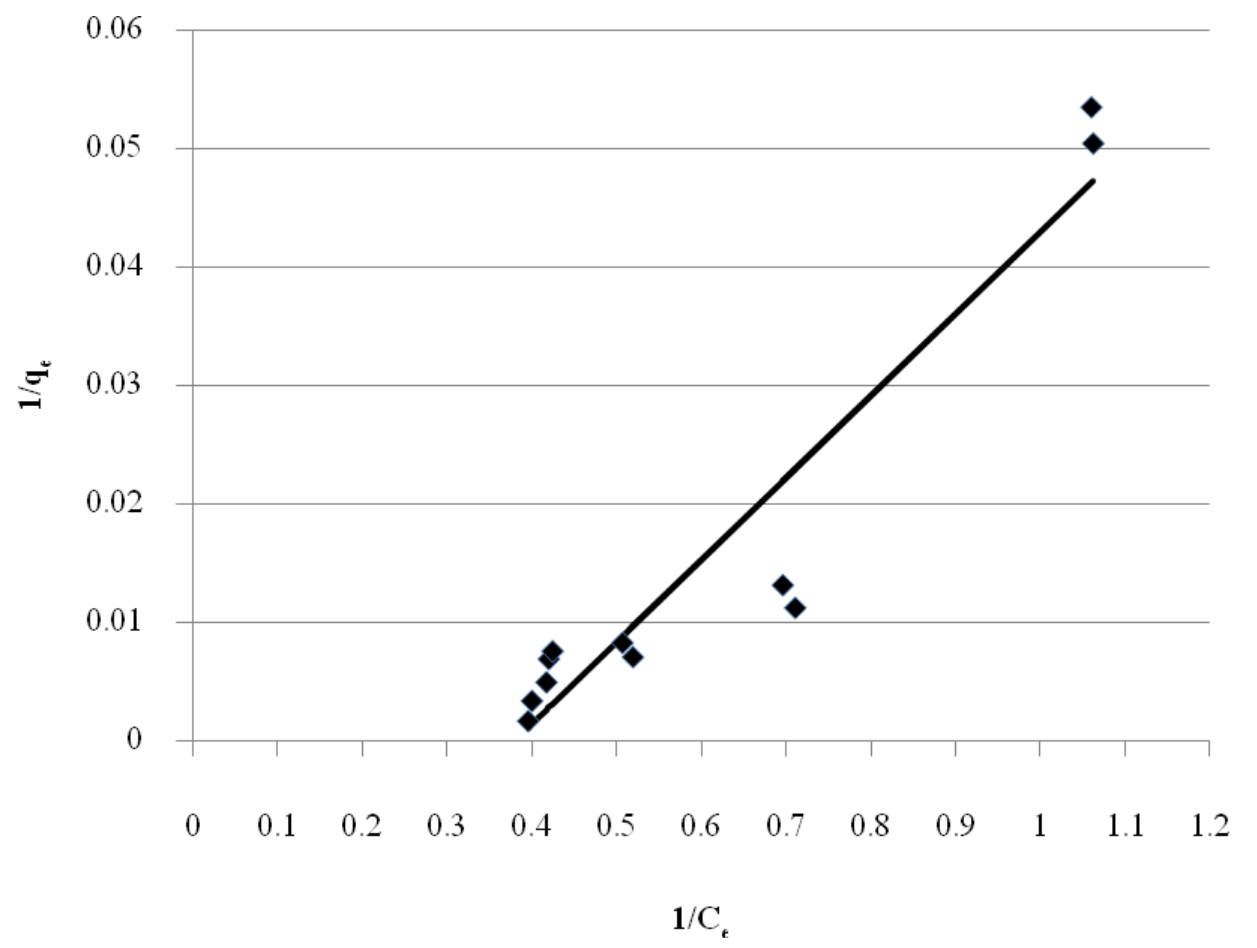

Fig. 9. Linear form of the Langmuir isotherm for the adsorption of FFA from CPO.

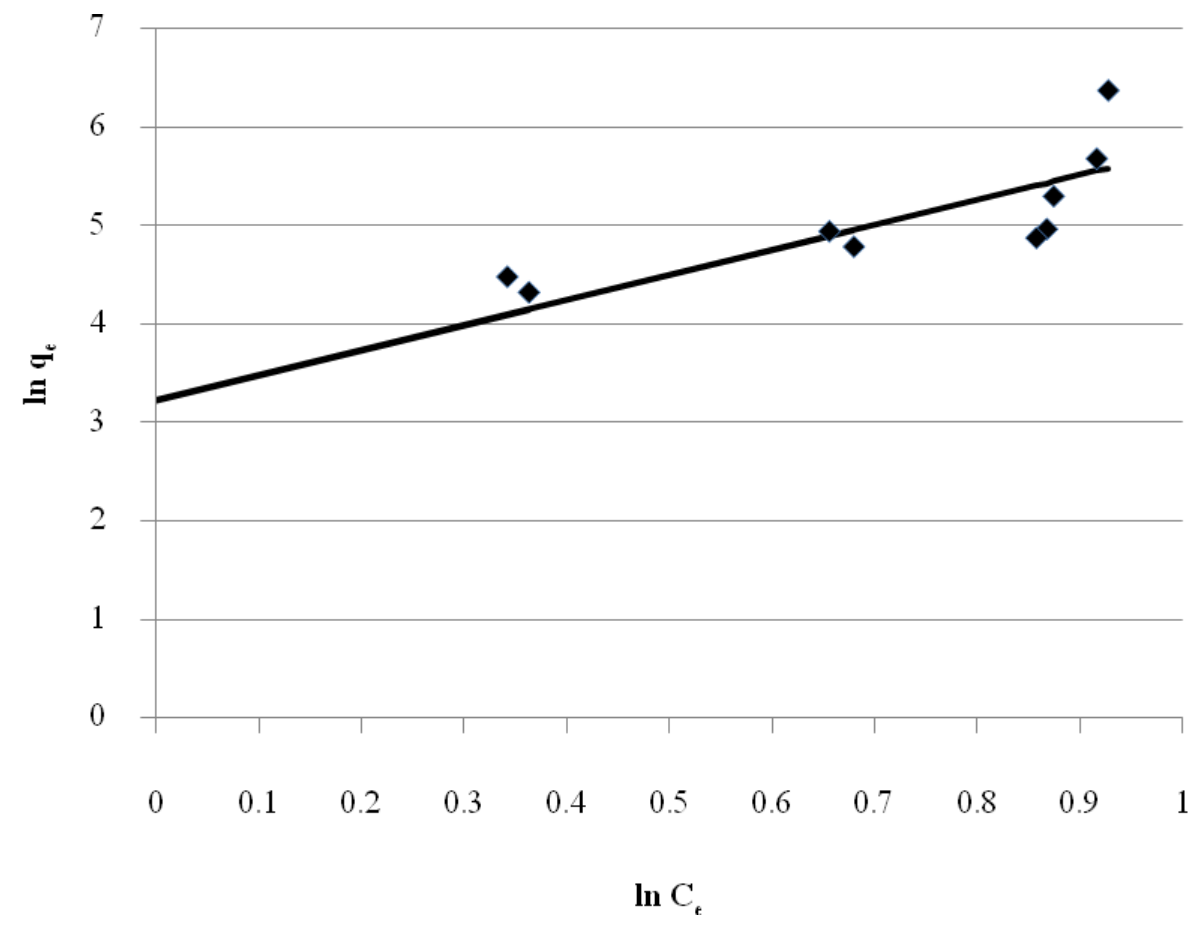

Fig. 10. Linear form of the Freundlich isotherm for the adsorption of FFA from CPO.

\section{Conclusion}

In this study, the use of rice husk, to synthesize magnesium silicate at different $\mathrm{SiO}_{2} / \mathrm{MgO}$ ratio were in the range of 1.99-3.96. They were amorphous with medium surface area and pore diameter. The adsorbents had some mesopore volume for large FFA molecules. The FFA adsorption on the magnesium silicate was carried out by adding 1 gram of the adsorbent to 50 grams of CPO for 1 hour. It 
was found that $\mathrm{SiO}_{2} / \mathrm{MgO}$ ratio of 1.99 had the highest adsorption capacities of $185 \mathrm{mg}$ of FFA per gram of adsorbent. In addition, higher $\mathrm{SiO}_{2} / \mathrm{MgO}$ ratio of magnesium silicate was found to reduce the adsorption capacities. The effect of dosage amount to equilibrium adsorption capacities showed decreasing in efficiency when dosage increased due to surplus amount of adsorbents. The experimental data could be better described by Freundlich isotherm than the Langmuir one because of values of maximum sorption capacity $\left(\mathrm{Q}^{0}\right)$ and Langmuir's sorption affinity (b) were minus which were physically meaningless. Moreover, FFA adsorption on magnesium silicate was both physisorption and chemisorption and well represented by the Fruenlich isotherm. Surprisingly, $\mathrm{SiO}_{2} / \mathrm{MgO}$ ratios of 1.99 having highest FFA adsorption capacity also had the highest amount of acid site. Large pore diameter and more mesopore volume could explain its high adsorption capacity. The adsorb sites on these adsorbents may be classified as FFA adsorption site and acidic site.

\section{Acknowledgement}

The authors express special thanks to the Faculty of Engineering, King Mongkut's Institute of Technology Ladkrabang for the financial support.

\section{References}

[1] R. V. Krishnarao, J. Subrahmanyam, and T. Jagadish Kumar, "Studies on the formation of black particles in rice husk silica ash," Journal of the European Ceramic Society, vol. 21, pp. 99-104, 2001.

[2] R. Santi, "Suitable condition for preparation of silica from rice husk ash," Master's Thesis, Prince of Songkla University, Songkla, 2004.

[3] P. Anorat, "Preparation of sodium silicate from rice husk ash using hydrothermal treatment," Master's thesis, King Mongkut's University of Technology North Bangkok, Bangkok, 2004.

[4] S. Suthida, "Production of ZSM-5 zeolite from rice husk ash," Master's thesis, Kasetsart University, Bangkok, 2004.

[5] S. Ozgul-Yucel, M. Tolay, S. Erdag, and S. Turkay, "Magnesium silicate synthesis from rice hull ash," JAOCS, Journal of the American Oil Chemists' Society, vol. 81, pp. 619-620, 2004.

[6] M. Berrios and R. L. Skelton, "Comparison of purification methods for biodiesel," Chemical Engineering Journal, vol. 144, pp. 459-465, 2008.

[7] R. A. Yates, J. D. Caldwell, and E. G. Perkins, "Diffuse reflectance fourier transform infrared spectroscopy of triacylglycerol and oleic acid adsorption on synthetic magnesium silicate," JAOCS, Journal of the American Oil Chemists' Society, vol. 74, pp. 289-292, 1997.

[8] M. Yurdakoç, M. Akçay, Y. Tonbul, and K. Yurdakoç, "Acidity of silica-alumina catalysts by amine titration using Hammett indicators and FT-IR study of pyridine adsorption," Turkish Journal of Chemistry, vol. 23, pp. 319-327, 1999.

[9] L. P. Hammett and A. J. Deyrup, "A series of simple basic indicators. I. The acidity functions of mixtures of sulfuric and perchloric acids with water," The Journal of the American Chemical Society, vol. 54, pp. 2721-2739, 1932.

[10] A. Proctor and S. Palaniappan, "Adsorption of soy oil free fatty acids by rice hull ash," JAOCS, Journal of the American Oil Chemists' Society, vol. 67, pp. 15-17, 1990. 
